\title{
Predictors of pain resolution after varicocelectomy for painful varicocele
}

\author{
Hyun Jun Park*, Seung Soo Lee* and Nam Cheol Park
}

Varicocelectomy is a management option for patients with painful varicocele. In this study, we assessed the effectiveness of varicocelectomy for painful varicocele and examined the factors that might be predictive of outcome. All patients who underwent a varicocelectomy for pain between February 2007 and July 2009 were included. A review of patient medical records was conducted; patient age, body mass index (BMI), grade, location of the varicocele, testicular volume, duration and quality of the pain (dull, dragging, throbbing or sharp) and surgical technique (inguinal versus subinguinal) were documented. All parameters were compared with the resolution of pain (complete, partial or failure). We followed up on 53 of 104 patients (51.0\%). Complete postoperative resolution of pain was reported by 28 patients $(52.8 \%)$, whereas $22(41.5 \%)$ reported partial resolution. Only three patients $(5.7 \%)$ reported failure. No relationship was observed between postoperative pain resolution and age, BMI, grade of varicocele, location of varicocele, ipsilateral testicular hypotrophy, quality of pain or surgical technique. The duration of pain before surgery was the only factor that correlated with postoperative pain resolution (univariate, $P=0.004$; multivariate, $P=0.002$ ). Our results indicate that varicocelectomy is an effective treatment for painful varicocele in properly selected patients, and that duration of pain before surgery may be predictive of outcome.

Asian Journal of Andrology (2011) 13, 754-758; doi:10.1038/aja.2010.87; published online 22 November 2010

Keywords: duration; pain; testis; varicocele; varicocelectomy

\section{INTRODUCTION}

A varicocele is a dilation of the scrotal portion of the pampiniform plexus and internal spermatic venous system. ${ }^{1}$ It accounts for $\sim 35 \%$ of cases of primary male infertility and is considered to be the most common cause of male infertility. ${ }^{2}$ Surgical repair of a varicocele is usually performed in patients complaining of infertility. About $2-10 \%$ of men with varicocele complain of pain, mainly in the scrotum or inguinal area. ${ }^{3}$ Conservative management may be offered to these patients, including limitation of physical activities, scrotal elevation and treatment with non-steroidal anti-inflammatory analgesics. However, these often do not contribute to pain management. ${ }^{4}$ Varicocelectomy is an alternative treatment for patients with painful varicocele who show no improvement after conservative management. ${ }^{5}$ Currently, few clinical studies have evaluated which patients with scrotal pain require a varicocelectomy and which clinical characteristics associated with varicocele can predict surgical outcomes. ${ }^{3,6-9}$ Moreover, the success rates of varicocelectomy for painful varicocele vary among studies. Symptom improvement has been reported in $>80 \%$ of patients after the surgical repair of a painful varicocele; $3,6,9,10$ however, Biggers and Soderdahl ${ }^{5}$ reported a relatively low rate of improvement (48\%). The variety of surgical success rates for treating painful varicocele and the lack of predictive parameters for surgical outcomes make it difficult for urologists treating patients with painful varicocele. In this study, we examined the effectiveness of surgical repair in patients with painful varicocele, and we examined the preoperative patient characteristics associated with postoperative symptom improvement.

\section{MATERIALS AND METHODS}

Materials

Between February 2007 and July 2009, 104 patients with varicocele underwent varicocelectomy performed by a single surgeon at the Pusan National University Hospital Department of Urology. A retrospective study was performed by reviewing the medical records of the patients. Of 104 subjects reviewed, 53 (51.0\%) underwent varicocelectomy to treat pain. Patients who had other causes of scrotal pain, such as epididymitis, orchitis, sexually transmitted disease, urinary tract infection, urolithiasis, prostatitis, inguinal hernia, testicular torsion, testicular tumor or trauma or a history of inguinal surgery, were excluded from the study. All 53 patients had undergone a trial of preoperative conservative management, consisting of scrotal support, non-steroidal anti-inflammatory medication and physical activity limitations, including no lifting of heavy materials or strenuous activity for a minimum of 3 weeks (maximum: 5; average: 4 ); however, no benefits in terms of pain resolution were noted in any patient. The surgical technique used for varicocele ligation included an inguinal or subinguinal approach with a surgical microscope. An assessment of each patient was made based on age, body mass index (BMI), varicocele grade, location of the varicocele, testicular hypotrophy, duration of pain, quality of pain and the surgical technique used. We 
developed a short self-administrated questionnaire to assess scrotal pain (duration and characteristics) and treatment outcomes (see Appendix).

\section{Methods}

Each patient was assigned to a group, according to age at surgery $(<20$, $21-29$ or $\geqslant 30$ years) and BMI $\left(<18.0,18.0-22.9\right.$ or $\left.\geqslant 23.0 \mathrm{~kg} \mathrm{~m}^{-2}\right)$. The varicocele was graded according to the criteria defined by Lyon et al. ${ }^{11}$ : Grade I, palpable only with the Valsalva maneuver; Grade II, palpable without the Valsalva maneuver; and Grade III, visible from a distance. The location of the varicocele was classified as unilateral or bilateral. The duration of pain was defined as that the period between the onset of the pain and surgery ( $<6$ or $\geqslant 6$ months). The patients were also classified according to the quality of pain (dull, dragging, throbbing or sharp), the surgical technique used (inguinal versus subinguinal) and testicular volume difference ( $<3$ or $\geqslant 3 \mathrm{ml})$. The testicular volume was determined using a Prader orchidometer. Ipsilateral testicular hypotrophy was defined as a testicular size discrepancy of $\geqslant 3 \mathrm{ml}^{12}$ In each group, the resolution of pain was classified as complete resolution, partial resolution or failure. Pain resolution was defined as complete or partial when there was total ablation or $\geqslant 70 \%$ reduction of symptoms such as pain or no further treatment was needed. Failure was defined as $<70 \%$ reduction and/or persistent symptoms.

\section{Statistical analysis}

Univariate analysis of the general linear model and multivariate linear regression analysis were conducted using SPSS for Windows version 15.0 (SPSS Inc., Chicago, IL, USA). $P<0.05$ was considered statistically significant.

\section{RESULTS}

The mean patient age was 25.7 years. Grade III varicocele was most prevalent, occurring in 44 patients $(83.0 \%)$, whereas grade II occurred in eight patients $(15.1 \%)$ and grade I in one patient (1.9\%). A leftsided unilateral varicocele was recorded in 48 patients $(90.6 \%)$; the remaining five patients $(9.4 \%)$ had a bilateral varicocele. All patients with a bilateral varicocele had bilateral pain and had undergone a bilateral varicocelectomy (Table 1).

The mean follow-up period after surgery was 12.4 months (range: 5-34 months). There were no intraoperative or postoperative complications. Among the 53 patients who underwent a varicocelectomy for pain, the pain was completely resolved in 28 patients $(52.8 \%)$, a partial resolution was observed in 22 patients $(41.5 \%)$ and 3 patients $(5.7 \%)$ reported failure (Figure 1).

Univariate analysis revealed no statistically significant correlation between BMI and pain resolution. However, multivariate analysis showed a statistically significant correlation $(P=0.042)$, in that the rate of postoperative improvement in symptoms was relatively higher in the normal BMI group (18.0-22.9 $\left.\mathrm{kg} \mathrm{m}^{-2}\right)$ than in the other groups. When the duration of pain before surgery was examined, the degree of improvement in postoperative symptoms was relatively higher in patients who had a shorter duration of pain ( $<6$ months) than in those who had a longer duration of pain ( $\geqslant 6$ months) (univariate, $P=0.004$; multivariate, $P=0.002$ ) (Table 2).

\section{DISCUSSION}

Treatment for painful varicocele usually starts with conservative treatments, including scrotal elevation, non-steroidal anti-inflammatory drugs and bed rest. In patients who are refractory to these treatment regimens, surgical correction has been performed. ${ }^{5,13}$ In this study, all

\section{Table 1 Patient characteristics}

\begin{tabular}{lc}
\hline Characteristics & Total $(\mathrm{n}=53)$ \\
\hline Age (years) & \\
Mean (range) & $25.7(12-67)$ \\
$<20$ & $17(32.1 \%)$ \\
$20-29$ & $21(39.6 \%)$ \\
$\geqslant 30$ & $15(28.3 \%)$ \\
BMI (kg m $\left.{ }^{-2}\right)$ & \\
Mean (range) & $21.9(16.0-27.2)$ \\
$<18.0$ & $4(7.5 \%)$ \\
$18.0-22.9$ & $31(58.5 \%)$ \\
$\geqslant 23.0$ & $18(34.0 \%)$ \\
Varicocele grade & $1(1.9 \%)$ \\
I & $8(15.1 \%)$ \\
II & $44(83.0 \%)$ \\
III & \\
Varicocele laterality & $48(90.6 \%)$ \\
Unilateral & $5(9.4 \%)$ \\
Bilateral & \\
Testis volume difference $(\mathrm{ml})^{\mathrm{a}}$ & $21(43.8)$ \\
$<3$ & $27(56.2)$ \\
$\geqslant 3$ & \\
Duration of pain (months) & $9.5(1-72)$ \\
Mean (range) & $34(64.2 \%)$ \\
$<6$ & $19(35.8 \%)$ \\
$\geqslant 6$ & $23(43.4 \%)$ \\
Quality of pain & $23(43.4 \%)$ \\
Dull & $2(3.8 \%)$ \\
Dragging & $5(9.4 \%)$ \\
Throbbing & $44(83.0 \%)$ \\
Sharp & $9(17.0 \%)$ \\
Surgical technique & \\
Inguinal & \\
Subinguinal & \\
\hline & \\
\hline &
\end{tabular}

Abbreviation: BMI, body mass index.

${ }^{a}$ Unilateral varicocele.

patients had undergone a course of conservative management before surgery, but no improvement was observed in any case.

In this study of 104 patients with varicocele, 53 (50.9\%) had undergone surgery for the management of pain. Most of these patients were unmarried adolescents or young adults who underwent surgery for pain only, with no consideration of infertility. Of these patients, $52.8 \%$ experienced complete resolution, whereas $41.5 \%$ experienced partial

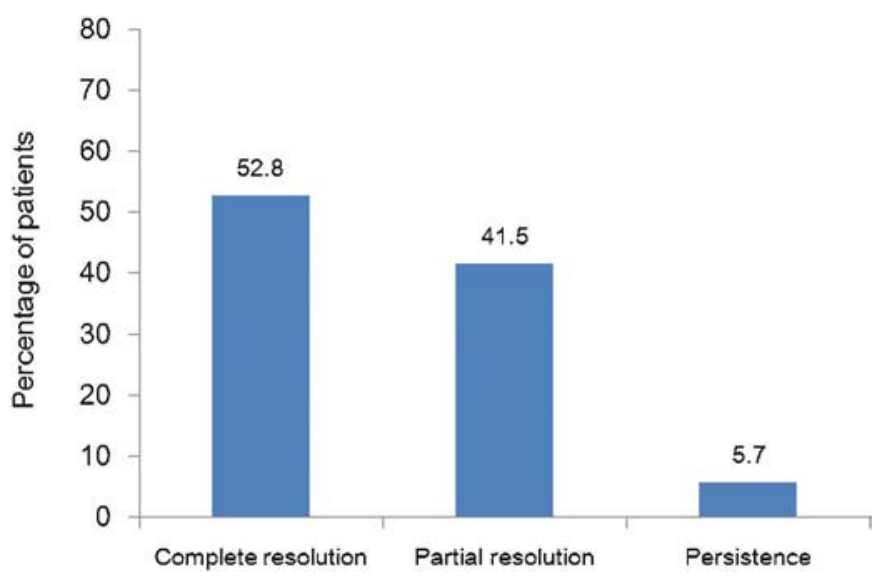

Figure 1 Postoperative outcomes of patients who underwent varicocelectomy. 
Table 2 Relationships between preoperative characteristics and postoperative improvements in pain according to univariate and multivariate analyses

\begin{tabular}{|c|c|c|c|c|c|}
\hline Factors & Complete resolution (n (\%)) & Partial resolution (n (\%)) & Failure (n (\%)) & $\mathrm{P}$ value & $\frac{\text { Multivariate analysis }}{\mathrm{P} \text { value }}$ \\
\hline Age (years) & & & & $0.367^{\mathrm{a}}$ & $0.761^{b}$ \\
\hline $20-29$ & $13(61.9)$ & $7(33.3)$ & $1(4.8)$ & & \\
\hline$\geqslant 30$ & $8(53.3)$ & $6(40)$ & $1(6.7)$ & & \\
\hline BMI $\left(\mathrm{kg} \mathrm{m}^{-2}\right)$ & & & & $0.244^{\mathrm{a}}$ & $0.042^{b}$ \\
\hline$\geqslant 23.0$ & $10(55.5)$ & $5(27.8)$ & $3(16.7)$ & & \\
\hline Grade & & & & $0.676^{a}$ & $0.982^{\mathrm{b}}$ \\
\hline । & $1(100)$ & $0(0)$ & $0(0)$ & & \\
\hline$\|$ & $4(50)$ & $3(37.5)$ & $1(12.5)$ & & \\
\hline III & 23 (52.3) & 19 (43.2) & $2(4.5)$ & & \\
\hline Location & & & & $0.716^{\mathrm{a}}$ & $0.872^{\mathrm{b}}$ \\
\hline$\geqslant 3$ & $16(59.3)$ & $10(37.0)$ & $1(3.7)$ & & \\
\hline Duration of pain (months) & & & & $0.004^{\mathrm{a}}$ & $0.002^{\mathrm{b}}$ \\
\hline$<6$ & $15(44.1)$ & $19(55.9)$ & $0(0)$ & & \\
\hline$\geqslant 6$ & $13(68.4)$ & $3(15.8)$ & $3(15.8)$ & & \\
\hline Quality of pain & & & & $0.874^{\mathrm{a}}$ & $0.924^{b}$ \\
\hline Dull & $13(56.5)$ & $9(39.1)$ & $1(4.4)$ & & \\
\hline Dragging & $12(52.2)$ & $9(39.1)$ & $2(8.7)$ & & \\
\hline Throbbing & $1(50)$ & $1(50)$ & $0(0)$ & & \\
\hline Sharp & $2(40)$ & $3(60)$ & $0(0)$ & & \\
\hline Surgical technique & & & & $0.374^{\mathrm{a}}$ & $0.169^{b}$ \\
\hline Inguinal & $24(54.4)$ & $18(40.9)$ & $2(4.6)$ & & \\
\hline Subinguinal & $4(44.5)$ & $4(44.5)$ & $1(11.0)$ & & \\
\hline
\end{tabular}

Abbreviation: BMI, body mass index.

a Univariate analysis of the general linear model.

${ }^{\mathrm{b}}$ Multivariate linear regression analysis.

${ }^{\mathrm{c}}$ Unilateral varicocele.

resolution of their pain after surgery. Table 3 shows a comparison of studies on the surgical treatment of painful varicocele. The overall improvement rate, including complete and partial pain resolution, in this study, was consistent with those in other studies in which the rate of symptom improvement ranged between 79 and 94\%, confirming the effectiveness of surgical repair for the treatment of painful varicocele; ${ }^{3,6-8,13}$ however, we found a lower rate of complete resolution and a higher rate of partial resolution. This difference could be related to the short postoperative follow-up duration. If we had evaluated the surgical outcomes with a longer follow-up period, the rate of complete resolution might have been different. In terms of the quality of pain before surgery, Peterson et al. ${ }^{3}$ reported that the surgical outcomes were poor in patients with sharp or radiating pain toward the femoral or inguinal area. The intensity of preoperative pain was related to postoperative pain resolution in a study by Kim et al. ${ }^{7}$ In our series, the quality of pain was classified as dull, dragging, throbbing or sharp. However, there was no significant correlation between the quality of pain and the degree of postoperative pain improvement.

Yaman et al. ${ }^{6}$ reported that the failure rate was associated with a high varicocele grade before surgery. In our series, the preoperative varicocele grades were not significantly associated with the loss of pain, on the basis of univariate and multivariate analyses.

Although several studies have attempted to identify an association between varicocele characteristics and postoperative pain resolution, we examined whether body characteristics are related to the outcomes for the first time and found that BMI was significantly associated with an improvement in postoperative pain. There have been studies of the correlation between body characteristics and the occurrence of varicocele. Zohalsky et al. ${ }^{14}$ reported that the incidence of varicocele decreased as body weight increased. Stavropoulos et al. ${ }^{15}$ also noted that the incidence of varicocele increased as body weight decreased. We found that BMI was significantly associated with an improvement in postoperative pain; however, additional studies are required to examine the pathophysiological mechanism by which body weight or BMI affects pain in patients with varicocele.

In this study, we also analyzed the correlation between surgical outcome and the time frame between the onset of pain and surgery. As we indicate in Table 2, complete resolution seemed to be higher in the group who had more than 6 months of pain before surgery duration; however, overall pain resolution, which we took to be a successful outcome and was defined as $>70 \%$ pain resolution, was higher in the group who had $<6$ months of pain before surgery ( $100 \%$ versus $84.2 \%)$. For this reason, we concluded that $<6$ months between the onset of pain and surgery results in greater success. It is assumed that other diseases that are unrelated to varicocele but cause pain in the inguinal region, such as chronic prostatitis or chronic orchialgia, might be present concurrently in patients experiencing long-term pain. Conversely, Altunoluk et al. ${ }^{9}$ reported that the success rate in 
Table 3 Comparison of previous studies and present study

\begin{tabular}{|c|c|c|c|c|c|c|c|c|c|}
\hline Reference no. & 5 & 3 & 6 & 7 & 10 & 8 & 13 & 9 & Present study \\
\hline No. of patients & 50 & 35 & 82 & 103 & 87 & 121 & 38 & 237 & 53 \\
\hline Mean age (years) & 20.7 & 25.7 & NA (8-40) & 21 & 26 & 21.8 & NA (14-16) & 23.7 & 25.7 \\
\hline $\begin{array}{l}\text { Duration of pain } \\
\text { (months) }\end{array}$ & 13.8 & 17.8 & NA & 11.6 & 16 & 17.3 & NA & 11.2 & 9.5 \\
\hline $\begin{array}{l}\text { Preoperative } \\
\text { conservative } \\
\text { therapy }(n(\%))\end{array}$ & $19(38)$ & $35(100)$ & $82(100)$ & $103(100)$ & $87(100)$ & $56(46.3)$ & NA & $237(100)$ & $53(100)$ \\
\hline Bilateral & NA & $5(14.3)$ & $12(14.6)$ & NA & $5(5.7)$ & NA & NA & $35(15)$ & $5(9.4)$ \\
\hline Right & NA & $0(0)$ & $0(0)$ & NA & $0(0)$ & NA & NA & $0(0)$ & $0(0)$ \\
\hline \multicolumn{10}{|l|}{ Grade $(n(\%))$} \\
\hline I & NA & $1(2.9)$ & $10(14.3)$ & $0(0)$ & 17 (19.5) & $10(8.3)$ & $0(0)$ & $9(3.8)$ & $1(1.9)$ \\
\hline ॥ & NA & $16(45.7)$ & $34(48.6)$ & $40(38.8)$ & $34(39.1)$ & $57(47.1)$ & $9(23.7)$ & $67(28.3)$ & $8(15.1)$ \\
\hline III & NA & $18(51.4)$ & $26(37.1)$ & $63(61.2)$ & $36(41.4)$ & $54(44.6)$ & $29(76.3)$ & 161 (67.9) & $44(83)$ \\
\hline Sharp & NA & $2(6)$ & NA & $33(32)$ & $6(6.9)$ & 19 (15.7) & NA & NA & $5(9.4)$ \\
\hline \multicolumn{10}{|c|}{ Surgical techniques $(n(\%))$} \\
\hline Retroperitoneal & $50(100)$ & $10(28.6)$ & $0(0)$ & $40(38.8)$ & $87(100)$ & $0(0)$ & $0(0)$ & $0(0)$ & $0(0)$ \\
\hline Inguinal & $0(0)$ & $0(0)$ & $0(0)$ & $41(39.8)$ & $0(0)$ & $28(23.1)$ & $24(63.2)$ & $0(0)$ & $44(83)$ \\
\hline Subinguinal & $0(0)$ & $24(68.6)$ & $82(100)$ & $22(21.4)$ & $0(0)$ & 93 (76.9) & $0(0)$ & $237(100)$ & $9(17)$ \\
\hline \multirow[t]{2}{*}{ Laparoscopic } & $0(0)$ & $1(2.8)$ & $0(0)$ & $0(0)$ & $0(0)$ & $0(0)$ & $14(36.8)$ & $0(0)$ & $0(0)$ \\
\hline & $0(0)$ & $0(0)$ & $0(0)$ & $0(0)$ & $0(0)$ & $0(0)$ & $0(0)$ & $0(0)$ & $0(0)$ \\
\hline \multicolumn{10}{|c|}{ Pain resolution $(n(\%))$} \\
\hline Complete & $24(48)$ & $30(86)$ & $72(87.8)$ & $81(78.6)$ & $72(82.8)$ & $74(61.2)$ & $26(68.4)$ & 203 (85.6) & $28(52.8)$ \\
\hline Partial & $0(0)$ & $1(3)$ & $4(4.9)$ & $10(9.7)$ & $8(9.2)$ & 27 (22.3) & $4(10.5)$ & $15(6.3)$ & $22(41.5)$ \\
\hline Failure & $26(52)$ & $4(11)$ & $6(7.3)$ & $12(11.6)$ & $7(8)$ & $20(16.5)$ & $8(21.1)$ & $19(8.1)$ & $3(5.7)$ \\
\hline $\begin{array}{l}\text { Duration of follow- } \\
\text { up (months) }\end{array}$ & NA & 10.9 & NA & NA & 36 & 4.7 & 6 & 3 & 12.4 \\
\hline
\end{tabular}

Abbreviations: BMI, body mass index; NA, not applicable.

patients with a long period ( $\geqslant 3$ months) of pain was higher than in those patients with a shorter duration of pain. However, there was a difference in the duration criteria between our (6 months) and Altunoluk's (3 months) study. Thus, further study is required to substantiate the association of pain duration before surgery with the postoperative surgical outcome.

The reported failure rate according to surgical technique varies among studies, and no significant differences have been observed. ${ }^{3,7,13}$ Only one study ${ }^{8}$ has shown a significant difference in the postoperative success rate between patients who underwent external spermatic vein ligation and those who did not, suggesting that cremasteric muscle ischemia may have a significant role as the cause of pain in varicocele. However, no data in the published literature support this hypothesis. We examined the difference in surgical success between inguinal and subinguinal approaches, but no significant difference was observed. However, we had only nine patients who underwent a subinguinal procedure. Hence, additional studies are warranted to examine the relationship between surgical procedure and pain resolution.

We did not observe any recurrent or persistent varicocele among the patients without pain resolution, in accordance with the studies of Yaman et al. ${ }^{6}$ and Altunoluk et al. ${ }^{9}$ It is thought that pain persistence is probably not related to varicocele recurrence.
There are several important limitations to this study. First is the lack of a randomized design and the small number of patients. Moreover, the lack of an even distribution of patients for grade, location of varicocele and operative technique (subinguinal versus inguinal) may have resulted in bias. Second, this was not a prospective study. Therefore, we assume that there was insufficient consideration of the differences in pre- and postoperative symptoms or of other comorbidities. Finally, we did not use an internationally validated questionnaire and did not quantify the pain intensity.

In conclusion, our data suggest that varicocele ligation for pain is successful when performed in properly selected patients in whom conservative management has failed. In addition, there was a significant correlation between symptom improvement and a short duration of pain before surgery.

\section{AUTHOR CONTRIBUTIONS}

NCP designed the study. HJP and SSL collected data, analyzed data, interpreted the data and wrote the paper.

\section{COMPETING FINANCIAL INTERESTS}

The authors declare no competing financial interests. 


\section{ACKNOWLEDGMENTS}

This study was supported by a Medical Research Institute Grant (2007-24) from Pusan National University Hospital.

1 Schneck FX, Bellinger MF. Abnormalities of the testes and scrotum and their surgical management. In: Wein AJ, Kavoussi LR, Novick AC, Partin AW, Peters CA, editors. Campbell-Walsh Urology. 9th ed. Philadelphia, PA: Saunders; 2007. pp3794-7.

2 Witt MA, Lipshultz LI. Varicocele: a progressive or static lesion? Urology 1993; 42 : 541-3.

3 Peterson AC, Lance RS, Ruiz HE. Outcomes of varicocele ligation done for pain. J Urol 1998; 159: 1565-7.

4 Lissoos I, Spiro FI. Non-operative treatment of varicocele. S Afr Med J 1986; 70: 8056.

5 Biggers RD, Soderdahl DW. The painful varicocele. Mil Med 1981; 146: 440-1.

6 Yaman Ö, Özdiler E, Anafarta K, Göğüș O. Effect of microsurgical subinguinal varicocele ligation to treat pain. Urology 2000; 55: 107-8.

$7 \mathrm{Kim}$ JS, Min SK, Jo MK. Effect of varicocele ligation for patients with painful varicocele. Korean J Urol 2001; 42: 732-5.

8 Karademir K, Enkul T, Baykal K, Ate F, Işeri C et al. Evaluation of the role of varicocelectomy including external spermatic vein ligation in patients with scrotal pain. Int J Urol 2005; 12: 484-8.

9 Altunoluk B, Soylemez H, Efe E, Malkoc O. Duration of preoperative scrotal pain may predict the success of microsurgical varicocelectomy. Int Braz J Urol 2010; 36: 55-9.

10 Yeniyol CO, Tuna A, Yener H, Zeyrek N, Tilki A. High ligation to treat pain in varicocele. Int Urol Nephrol 2003; 35: 65-8.

11 Lyon RP, Marshall S, Scott MP. Varicocele in childhood and adolescence: implication in adulthood infertility. Urology 1982; 19: 641-4.

12 Sigman M, Jarow JP. Ipsilateral testicular hypotrophy is associated with decreased sperm counts in infertile men with varicoceles. J Urol 1997; 158: 605-7.
13 Zampieri N, Ottolenghi A, Camoglio FS. Painful varicocele in pediatric age: is there a correlation between pain, testicular damage and hormonal values to justify surgery? Pediatr Surg Int 2008; 24: 1235-8.

14 Zohalsky MP, Zoltan E, Nagler HM. The impact of height, weight and BMI (body mass index) on the incidence and significance of varicoceles. Fertil Steril 2002; 78(Suppl 1): 263.

15 Stavropoulos NE, Mihailidis I, Hastazeris K, Moisidou R, Louka G et al. Varicocele in schoolboys. Arch Androl 2002; 48: 187-92.

\section{APPENDIX}

\section{Questionnaire for the assessment of scrotal pain and treatment} outcome

-Preoperative

Question 1: How long have you been suffering from scrotal pain?

a. less than 6 months

b. longer than 6 months

Question 2: How would you characterize your scrotal pain?

a. dull

b. dragging

c. throbbing

d. sharp

-Postoperative

Question 3: How do you feel after surgery?

a. completely resolution of pain

b. partially resolved pain (greater than $70 \%$ reduction)

c. persistent pain or a less than $70 \%$ reduction 